Article

\title{
An Innovative Agro-Forestry Supply Chain for Residual Biomass: Physicochemical Characterisation of Biochar from Olive and Hazelnut Pellets
}

\author{
Ilaria Zambon ${ }^{1}$, Fabrizio Colosimo ${ }^{2}$, Danilo Monarca ${ }^{1}$, Massimo Cecchini ${ }^{1}$, \\ Francesco Gallucci ${ }^{3}$, Andrea Rosario Proto ${ }^{4}$, Richard Lord ${ }^{2}$ and Andrea Colantoni ${ }^{1, *}$ \\ 1 Department of Agricultural and Forestry Sciences (DAFNE), Tuscia University, Via San Camillo de Lellis snc, \\ Viterbo 01100, Italy; ilaria.zambon@unitus.it (I.Z.); monarca@unitus.it (D.M.); cecchini@unitus.it (M.C.) \\ 2 Department of Civil and Environmental Engineering, University of Strathclyde, 75 Montrose Street, \\ Glasgow G1 1XJ, UK; fabrizio.colosimo@strath.ac.uk (F.C.); richard.lord@strath.ac.uk (R.L.) \\ 3 Council for Agricultural Research and Agricultural Economy Analysis (CREA) Research Unit for \\ Agricultural Engineering, Via della Pascolare 16, Monterotondo, Rome 00015, Italy; \\ francesco.gallucci@crea.gov.it \\ 4 Department of Agriculture, Mediterranean University of Reggio Calabria, Feo di Vito, \\ Reggio Calabria 89122, Italy; andrea.proto@unirc.it \\ * Correspondence: colantoni@unitus.it; Tel.: +39-07-6135-7356
}

Academic Editor: Mejdi Jeguirim

Received: 9 April 2016; Accepted: 1 July 2016; Published: 9 July 2016

\begin{abstract}
Concerns about climate change and food productivity have spurred interest in biochar, a form of charred organic material typically used in agriculture to improve soil productivity and as a means of carbon sequestration. An innovative approach in agriculture is the use of agro-forestry waste for the production of soil fertilisers for agricultural purposes and as a source of energy. A common agricultural practice is to burn crop residues in the field to produce ashes that can be used as soil fertilisers. This approach is able to supply plants with certain nutrients, such as $\mathrm{Ca}, \mathrm{K}, \mathrm{Mg}, \mathrm{Na}, \mathrm{B}, \mathrm{S}$, and Mo. However, the low concentration of $\mathrm{N}$ and $\mathrm{P}$ in the ashes, together with the occasional presence of heavy metals $(\mathrm{Ni}, \mathrm{Pb}, \mathrm{Cd}, \mathrm{Se}, \mathrm{Al}$, etc.), has a negative effect on soil and, therefore, crop productivity. This work describes the opportunity to create an innovative supply chain from agricultural waste biomass. Olive (Olea europaea) and hazelnut (Corylus avellana) pruning residues represent a major component of biomass waste in the area of Viterbo (Italy). In this study, we evaluated the production of biochar from these residues. Furthermore, a physicochemical characterisation of the produced biochar was performed to assess the quality of the two biochars according to the standards of the European Biochar Certificate (EBC). The results of this study indicate the cost-effective production of high-quality biochar from olive and hazelnut biomass residues.
\end{abstract}

Keywords: biochar; biomass; soil fertiliser; olive; hazelnut

\section{Introduction}

Biochar is a carbon-rich material produced by thermal decomposition of biomass under oxygen-limited conditions [1]. According to the International Biochar Initiative (IBI), biochar is primarily used for soil applications for both agricultural and environmental gains [2]. The IBI definition differentiates biochar from charcoal, whose use is as a fuel for heat, as an absorbent material, or as a reducing agent in metallurgical processes [1,3]. Thermo-chemical processes include (i) slow pyrolysis (conventional carbonization); (ii) fast pyrolysis; (iii) flash carbonization; and (iv) gasification [4-7]. During the last two decades, pyrolysis process received more attention from the scientific community, since it is an efficient method for converting biomass into bio-fuel $[5,8]$. The pyrolysis process and its 
parameters, such as final temperature, pressure, heating rate, and residence time, greatly influence biochar quality [5]. The advantage of slow pyrolysis is to retain up to $50 \%$ of the carbon (C) feedstock in stable biochar [9], which makes it suitable as soil fertiliser. High-temperature pyrolysis $\left(>550^{\circ} \mathrm{C}\right)$ produces biochar with high aromatic content and, therefore, recalcitrant to decomposition [10]. Biochars produced through low-temperature processes $\left(<550^{\circ} \mathrm{C}\right)$ typically have a less-condensed $\mathrm{C}$ structure and are expected to give a better contribution to soil fertility [11]. The nature of the biomass feedstock also influences the properties of the produced biochar $[3,12]$. The relation between biochar properties and its potential to improve agricultural soils is a nascent focus area and the appropriate pyrolysis conditions are still unclear [13]. Numerous recent studies focused on methodologies for the chemical characterisation of biochars [13-15], other studies investigated the intrinsic potential of biochar as a soil amendment [16,17], although further efforts are required to obtain biochar with suitable properties [3]. One of the attractive characteristics of biochar as a soil amendment is its porous structure, which improves water retention and increases soil surface area [2]. Moreover, the concentration of biochar into soil has been related to an improved nutrient use efficiency, either through nutrients contained in biochar or through physicochemical processes that allow a better uptake of soil-inherent or fertiliser-derived nutrients [2]. The application of biochar increases physical and chemical qualities of soils, resulting in greater productivity of the agro-ecosystem [18]. Biochar, due to its biological and chemical stability, can also act as a $\mathrm{C}$ sink. The recalcitrance of biochar to microbial degradation enables the long-term sequestration of $C$ in soil $[2,19]$.

Biochar application in agriculture, positively affects the water holding capacity; this property derives from the distribution and the degree of cohesion of the pores in biochar, which depends on the particles size and aggregation, as well as the organic matter (OM) content. The effect of biochar on water holding capacity is dependent on both the high internal surface area of biochar and the capability to aggregate soil particles with $\mathrm{OM}$, minerals, and microorganisms. The increase in soil porosity also allows a better percolation of excess water towards the deeper layers of the soil, therefore increasing ventilation.

This work aims to determine the opportunity to create an innovative supply chain from agricultural waste biomass, especially regarding olive (Olea europaea) and hazelnut (Corylus avellana) in order to evaluate the production of biochar from their pruning residues. Biomass residues in Mediterranean areas come mainly from agricultural and agro-industrial activities, as well as forest by-products. Only a few woody residues are used to produce fertilisers and as renewable energy resources [20]. In contrast, typical management strategies in the agricultural industry do not provide any valorisation of these biomasses, which are burnt in the field to prevent proliferation of plant diseases [20]. However, this landfill choice affects the soil structure since OM in woody biomass residues must be completely decomposed before used as fertiliser.

\section{Materials and Methods}

\subsection{Biomass from Olive and Hazelnut Prunings}

In the area of Viterbo, pruning residues from olive and hazelnut are rarely utilised as a source of energy in burning stoves or boilers; they are, instead, burnt in situ, therefore reducing the formation of soil organic carbon. During summer, besides pruning residues, suckers are removed before the harvest, representing another significant loss of biomass. Approximately $15 \mathrm{~m}^{3}$ of biomass samples from both olive and hazelnut have been collected in farms of the Viterbo province. Recent studies [21,22] have investigated the possibility of enhancing olive and hazelnut residue waste management as a means to produce soil fertilisers and energy, therefore reducing the environmental impact of such residual organic wastes. Biomass from pruning crop operations (Figure 1a,b) represents an attractive resource that could be exploited for (i) fuel production (combustion and/or gasification) and (ii) biochar production (pyrolysis) that can be used as soil fertiliser. 

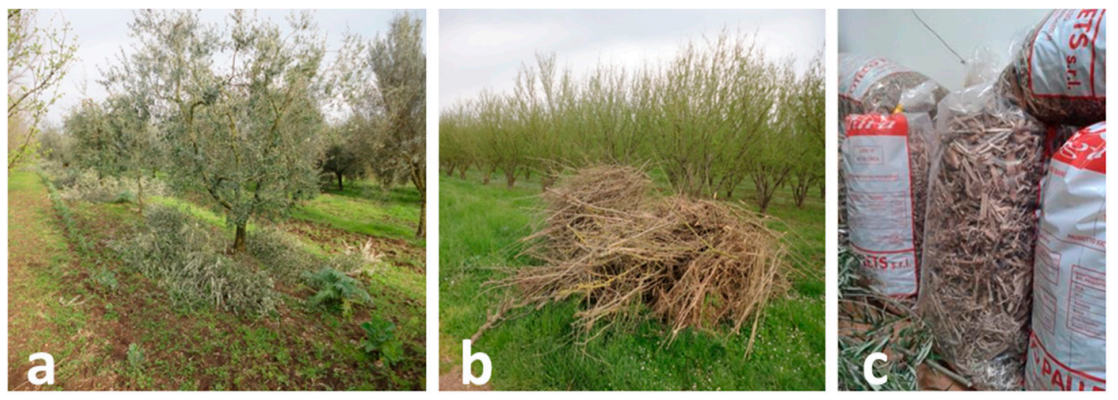

Figure 1. Pruning residues from (a) olive and (b) hazelnut after crop operations; and (c) bio-shredding.

A pelletization procedure was developed and applied on bio-shredding obtained from olive and hazelnut residues (Figure 1c). Pruning residues were collected on site and immediately transferred to the laboratory for sifting and exsiccation (Figure 2) until a water content of $15 \%$ was achieved. Final water content as low as $15 \%$ is necessary for further refining of the product and pellet production. The humidity concentration in the prunings is very notable, because we can improve the technical process for pellet production by biomass. In Italy there are not many companies and total supply chains that work the prunings for pellet production and for use of these residual agriculture sub-products (Figure 3).
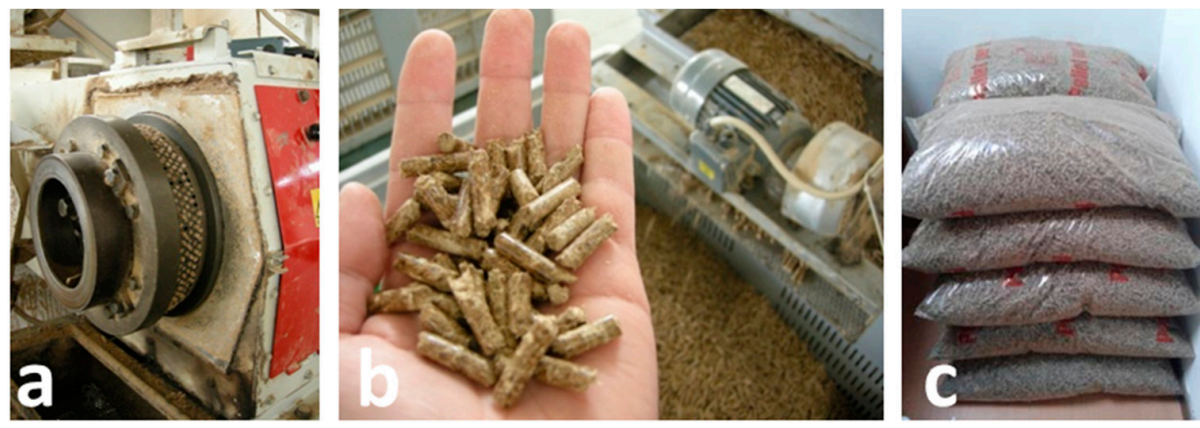

Figure 2. Schematic of the pelletization process showing (a) pellet mill; (b) olive and hazelnut pellet; and (c) packaging.
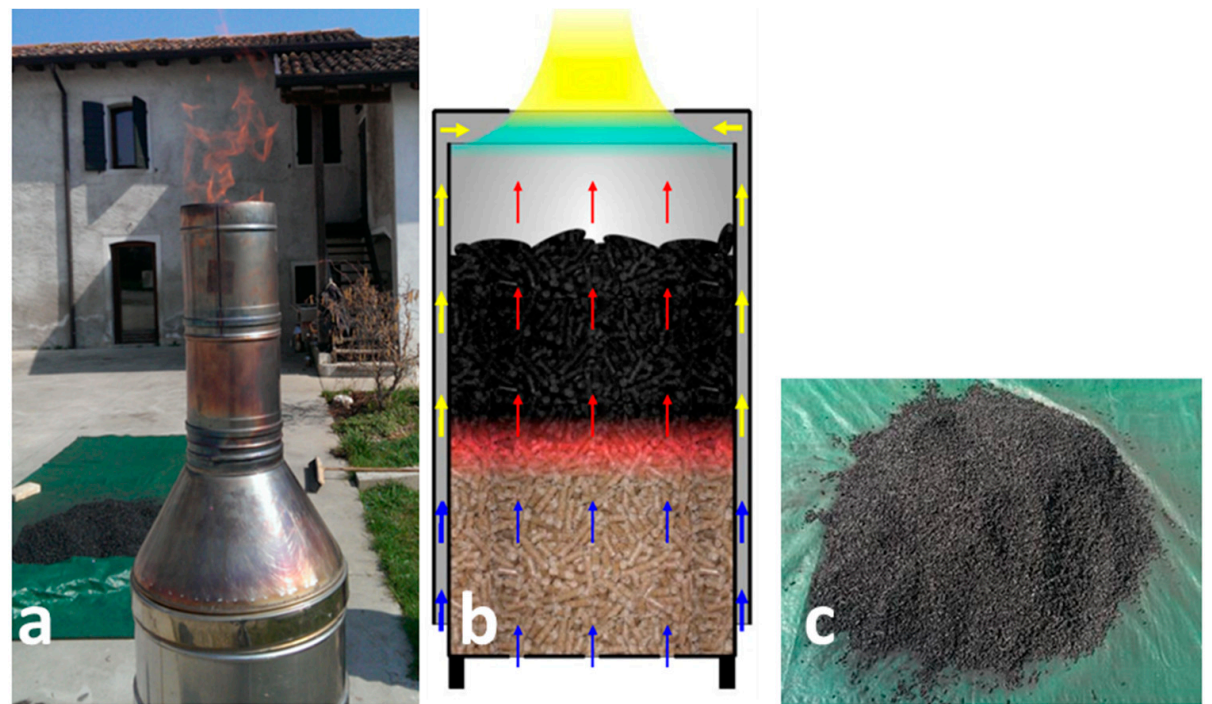

Figure 3. Biochar production from pellets showing (a) the Elsa Research carbonization system; (b) a schematic representation of the conversion process; and (c) the final product (biochar). 


\subsection{Pyrolysis Process}

Pyrolysis of biomass is commonly considered as a thermo-chemical conversion process $[7,23]$. Pyrolysis is carried out under partial (or complete) absence of oxygen and relies on capturing the off-gases from thermal decomposition of the organic materials [19]. The physicochemical characteristics of biochar are determined by the type of feedstock and by the temperature of pyrolysis. For example, higher salt and ash contents are expected in wheat straw than in wood-derived biochar [24], and C content and $\mathrm{N}$ content are greater in pine chips than in poultry litter-derived biochar [25]. A higher pyrolysis temperature results in greater surface area, lower biochar recovery, higher ash content, elevated $\mathrm{pH}$, minimal total surface charge [26], and lower cation exchange capacity [24]. Removal of volatile compounds at higher pyrolysis temperatures also cause biochars to have higher $\mathrm{C}$ content and lower hydrogen $(\mathrm{H})$ and $\mathrm{O}$ content [26]. Pyrolysis of agro-forestry residues is typically carried out with temperatures between 400 and $800^{\circ} \mathrm{C}$. With these conditions, the feedstock is converted to liquid products (so-called tar or pyrolysis oil) and/or gas (syngas), which can be used as fuels or raw materials for subsequent chemical transformation. The residual solid carbonaceous material obtained (biochar) could be further refined to products, such as activated carbon.

\subsection{Biochar Production form Olive and Hazelnut Pellets}

The carbonisation system Elsa Research (Blucomb Ltd., based in Udine, Italy) was used to produce the biochar from olive and hazelnut pellets; biomass conversion was achieved by pyrolytic micro-gasification (Figure 3). The Elsa Research carbonisation system works with natural ventilation and does not require being powered by batteries or electricity. A chimney is typically used to increase the air draft for fuels that have difficulties igniting.

Physicochemical characterisation of the biochar obtained from the Elsa Research carbonisation system was performed at the European Biochar Institute, which released the EBC based on the quality of the biochar.

\section{Results}

\subsection{From Biomass to Biochar: Conversion Rates Analyses}

Auto-thermal conversion of biomass was carried out under natural ventilation. Quantitative analyses of pyrolysed biomass and produced biochar, as well as the conversion rates, are reported for 10 and four sessions of pyrolysis, respectively, for olive and hazelnut pellets (Table 1). A statistical comparison between olive and hazelnut performances during pyrolysis is reported in Table 2, showing the total conversion rates, mean, and standard deviation (SD) of the results obtained in the experiments.

Table 1. Conversion rates of biomass obtained from each pyrolysis session.

\begin{tabular}{|c|c|c|c|c|c|c|c|}
\hline \multicolumn{4}{|c|}{ Olive } & \multicolumn{4}{|c|}{ Hazelnut } \\
\hline Session & $\begin{array}{l}\text { Biomass } \\
(\mathrm{kg})\end{array}$ & $\begin{array}{l}\text { Biochar } \\
(\mathrm{kg})\end{array}$ & $\begin{array}{c}\text { Conversion } \\
\text { Rate }\end{array}$ & Session & $\begin{array}{c}\text { Biomass } \\
(\mathrm{kg})\end{array}$ & $\begin{array}{l}\text { Biochar } \\
(\mathrm{kg})\end{array}$ & $\begin{array}{c}\text { Conversion } \\
\text { Rate }\end{array}$ \\
\hline 1 & 38.35 & 8.11 & 0.209 & 1 & 37.69 & 8.11 & 0.215 \\
\hline 2 & 39.07 & 8.21 & 0.210 & 2 & 36.25 & 7.96 & 0.220 \\
\hline 3 & 38.88 & 8.19 & 0.211 & 3 & 37.03 & 8.09 & 0.218 \\
\hline 4 & 38.96 & 8.16 & 0.209 & 4 & 37.11 & 8.09 & 0.218 \\
\hline 5 & 34.09 & 7.10 & 0.208 & & & & \\
\hline 6 & 39.02 & 8.23 & 0.211 & & & & \\
\hline 7 & 38.89 & 8.19 & 0.211 & & & & \\
\hline 8 & 38.93 & 8.19 & 0.210 & & & & \\
\hline 9 & 38.97 & 8.20 & 0.210 & & & & \\
\hline 10 & 38.81 & 8.13 & 0.209 & & & & \\
\hline
\end{tabular}


Table 2. Comparisons and statistical values of conversion rates of olive and hazelnut.

\begin{tabular}{ccccc}
\hline & \multicolumn{2}{c}{ Olive } & \multicolumn{2}{c}{ Hazelnut } \\
\cline { 2 - 5 } & Biochar $\mathbf{( k g )}$ & Conversion Rate & Biochar $\mathbf{( k g )}$ & Conversion Rate \\
\hline Total & 384.47 & 80.71 & 148.08 & 32.25 \\
Mean & & 0.210 & & 0.218 \\
SD & & 0.00088 & 0.00188 \\
\hline
\end{tabular}

Further analyses were carried out to investigate the calorific power of the two biochars produced. Composition, structure, heat value of the gas, tar liquid, and semi-char solid products depend on the pyrolysis temperature [7]. Quantity and quality of resulting outputs from biomass pyrolysis are related to the chemical composition of the operating temperature and the feedstock $[7,27]$. The calorific values calculated were compared with those provided by the producers in order to make energy considerations on the process. The results obtained are consistent with other pyrolysis processes. The latter led to the volatilisation of a fraction of biomass with a calorific value ranging between $75 \%$ and $85 \%$ of the starting biomass. The calorific value is measured in terms of the high calorific value [28]. Table 3 distinguishes two types of calorific value (usually expressed in $\mathrm{MJ} / \mathrm{kg}$ ): (i) the higher calorific value that it is the amount of heat produced by a complete combustion of a mass unit of a sample, at constant volume, in an atmosphere rich of oxygen at standard conditions $\left(25^{\circ} \mathrm{C}, 101.3 \mathrm{kPa}\right)$; and (ii) the lower calorific value (PCI) that does not include the heat of the condensation of water [28].

Table 3. Analysis of the calorific power of pyrolysis reaction for the two biochars produced in this study.

\begin{tabular}{cccc}
\hline Olive Wood & Units & Pellet & Biochar \\
\hline Higher calorific value & $\mathrm{MJ} / \mathrm{kg}$ & 19.47 & 31.71 \\
Lower calorific value & $\mathrm{MJ} / \mathrm{kg}$ & 16.17 & 30.48 \\
Calorific value from pyrolysis & $\mathrm{MJ} / \mathrm{kg}$ & \multicolumn{2}{c}{12.37} \\
Percentage of calorific value from pyrolysis & $\%$ & \multicolumn{2}{c}{0.76} \\
Hazelnut Wood & $\mathrm{Units}$ & Pellet & Biochar \\
Higher calorific value & $\mathrm{MJ} / \mathrm{kg}$ & 19.02 & 26.62 \\
Lower calorific value & $\mathrm{MJ} / \mathrm{kg}$ & 16.71 & 25.66 \\
Calorific value from pyrolysis & $\mathrm{MJ} / \mathrm{kg}$ & \multicolumn{2}{c}{14.21} \\
Percentage of calorific value from pyrolysis & $\%$ & \multicolumn{3}{c}{0.85} \\
\hline
\end{tabular}

Pyrolysis does not produce energy from heat; rather, it leads to the production of gas from biomass. In general, pyrolysis involves the heating of biomass to temperatures greater than $400{ }^{\circ} \mathrm{C}$ in the absence of oxygen [29]. At these temperatures, biomass thermally decomposes releasing a vapour phase and biochar (solid phase). On cooling the pyrolysis vapour, polar and high-molecular-weight compounds condense out as bio-oil (liquid phase) while low-molecular-weight volatile compounds remain in the gas phase (syngas) [6]. The physics and chemistry of pyrolysis process results are extremely complex, and are dependant depending on both the rector conditions and the nature of the biomass [29]. The combustion of gas in the Elsa Research system occurs in "close-coupled combustion" (micro-gasification). Biochars produced by Blucomb Ltd. (Udine, Italy) (spin-off) for the European project were analysed by Eurofins laboratories, accredited for the certification of the EBC. International biochar experts developed the EBC in order to consider it in the European context as a voluntary industrial standard [30]. The EBC guarantees a sustainable biochar production, with a low-risk use in agronomic systems. Biochar produced in accordance with the standards of the EBC fulfils all of the requirements of sustainable production and environmental impact by certifying (i) sustainable production and provision of biomass feedstock; (ii) energy efficient, low emission pyrolysis technique; (iii) low contaminant level in the biochar; and (iv) low hazard use and application of the biochar. These standards are in compliance with current environmental European regulations [31]. 


\subsection{Elemental Analysis}

The chemical composition of biochar is determined also by the source of biomass employed. Biochar produced from wood, for example, is denser and has higher $C$ content $(\sim 80 \%)$ [32]. These properties reflect the chemical complexity of lignin, which makes it more resistant to thermal degradation. The elemental composition, plotted as $\mathrm{H} / \mathrm{C}$ vs. $\mathrm{O} / \mathrm{C}$ ratios (Figure 4), is often used to describe maturity, decomposition rate, and combustion behaviour of fossil chars and coal [33,34]. When applied to biochar, the $\mathrm{H} / \mathrm{C}$ and $\mathrm{O} / \mathrm{C}$ ratios can be suitable indicators of the degree of carbonisation. High ratios typically point to primary plant macromolecules, such as simple carbohydrates and cellulose [35]. An $\mathrm{H} / \mathrm{C}$ ratio of $\leqslant 0.2$ indicates $\mathrm{C}$ of plant origin with elevated carbonisation [36].

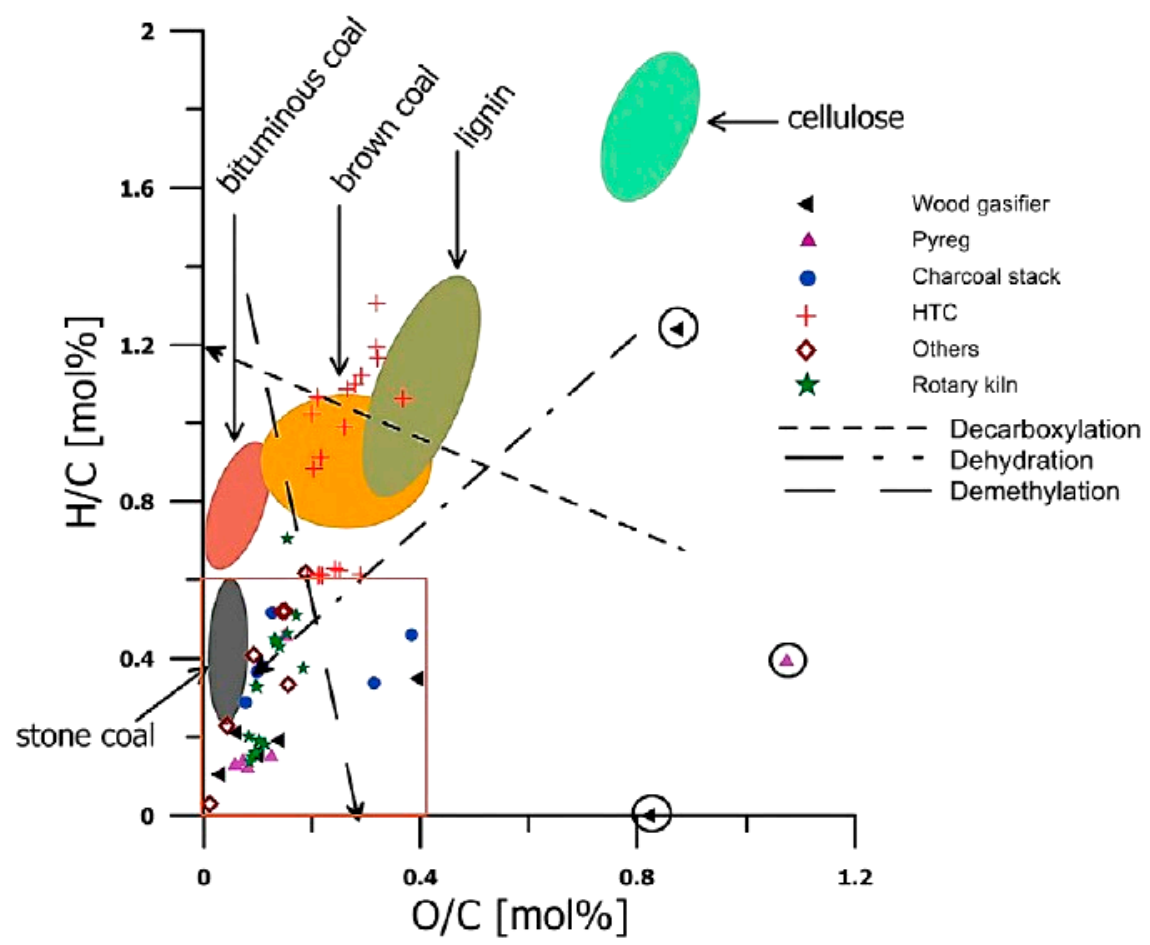

Figure 4. Example of Van Krevelen diagram of biochars obtained through different pyrolisis processes. The red square shows the optimum elemental ratio values of $\mathrm{H} / \mathrm{C}$ and $\mathrm{O} / \mathrm{C}$ for biochar production.

The $\mathrm{O} / \mathrm{C}$ ratio is an indicator of the presence of polar functional groups, which influence the stability of biochar by preventing a dense, graphite-like structure of the material [37]. Therefore, the $\mathrm{O} / \mathrm{C}$ ratio is useful to assess hydrophilicity and hydrophobicity of the charred material. The ratios of $\mathrm{H}, \mathrm{O}$, and $\mathrm{C}$ can also be used to differentiate between materials obtained by different processes. In the view of $C$ sequestration and for material with complex aromatic structure and low presence of functional groups, optimum ratios of $\mathrm{H} / \mathrm{C}$ and $\mathrm{O} / \mathrm{C}$ are approximately $\leqslant 0.6$ and $\leqslant 0.4$, respectively [38]. Nitrogen in biochar is an important nutrient, its concentration is related to the concentration in the starting material, with values between 1.8 and $56 \mathrm{~g} \cdot \mathrm{kg}^{-1}$, although $\mathrm{N}$ in biochar is in a form often not readily bioavailable [39]. The $\mathrm{C} / \mathrm{N}$ ratio, an indicator of the bioavailability of an organic compound, is highly variable and ranges between 7 and 500 [38].

The results of elemental analyses of the two biochars investigated in this study are reported in Table 4. Both biochars are characterised by values well below the limits established by the EBC, in particular the olive and hazelnut biochars have high values of $\mathrm{C}$ and low $\mathrm{H} / \mathrm{C}$ and $\mathrm{O} / \mathrm{C}$ ratios. A low $\mathrm{H} / \mathrm{C}$ ratio indicates that the produced biochars are also recalcitrant to microbial degradation. These results indicate that our production process yield high-quality biochars with a level of carbonisation that makes it suitable for $\mathrm{C}$ sequestration, as confirmed by the $\mathrm{H} / \mathrm{C}$ ratios. 
Table 4. Elemental analyses from EBC (Method DIN 51732).

\begin{tabular}{cccccc}
\hline Elements & Units & $\begin{array}{c}\text { Hazelnut } \\
\text { Biochar }\end{array}$ & $\begin{array}{c}\text { Olive } \\
\text { Biochar }\end{array}$ & $\begin{array}{c}\text { EBC Biochar } \\
\text { Base }\end{array}$ & $\begin{array}{c}\text { EBC Biochar } \\
\text { Premium }\end{array}$ \\
\hline H (Hydrogen) & $\% \mathrm{w} / \mathrm{w}$ & 1.21 & 1.58 & - & - \\
$\mathrm{C}$ (Carbon, total) & $\% \mathrm{w} / \mathrm{w}$ & 78.1 & 90.1 & $>50$ & $>50$ \\
$\mathrm{~N}$ (Nitrogen, total) & $\% \mathrm{w} / \mathrm{w}$ & 0.64 & 0.42 & - & - \\
O (Oxygen) & $\% \mathrm{w} / \mathrm{w}$ & 1.2 & 1.7 & - & - \\
Carbonate as CO $\mathbf{2}_{2}$ & $\% \mathrm{w} / \mathrm{w}$ & 2.62 & 1.17 & - & - \\
Carbonate (organic) & & 75.5 & 89.8 & & $<0.6$ \\
H/C ratio (molar) & & 0.18 & 0.21 & $<0.6$ & $<0.4$ \\
O/C rate (molar) & & 0.012 & 0.014 & $<0.4$ & \\
Sulphur (total) & $\% \mathrm{w} / \mathrm{w}$ & $\mathbf{0 . 0 7}$ & $<0.03$ & & \\
\hline
\end{tabular}

\subsection{Nutrients and Trace Elements}

Biomass residues containing high concentrations of minerals, such as those obtained from herbaceous plants produce biochars with high ash content [32], maintain in the biochar matrix most of the nutrients present in the starting material (Table 5). These types of biochar have a lower total carbon (TC) content and cohesion than those obtained from wood-pruning biomass. The low C content, together with elevated concentrations of nutrients, makes biochars from herbaceous material more readily available for microorganisms [2]. The concentration of phosphorus $(\mathrm{P})$ and potassium $(\mathrm{K})$ in the biochar is related to the initial content in the feedstock. The content of $\mathrm{P}$ and $\mathrm{K}$ are typically between 2.7 and $480 \mathrm{~g} \cdot \mathrm{kg}^{-1}$ and 10 to $58 \mathrm{~g} \cdot \mathrm{kg}^{-1}$, respectively [39].

Table 5. Determination from microwave digestion (method: DIN 22022-1).

\begin{tabular}{clccccc}
\hline Elements & Units & Methods & $\begin{array}{c}\text { Hazelnut } \\
\text { Biochar }\end{array}$ & $\begin{array}{c}\text { Olive } \\
\text { Biochar }\end{array}$ & $\begin{array}{c}\text { EBC Biochar } \\
\text { Base }\end{array}$ & $\begin{array}{c}\text { EBC Biochar } \\
\text { Premium }\end{array}$ \\
\hline $\mathrm{P}$ (Phosphorus) & $\mathrm{mg} / \mathrm{kg}$ & ISO 11885 & 590 & 330 & - & - \\
$\mathrm{Mg}$ (Magnesium) & $\mathrm{mg} / \mathrm{kg}$ & ISO 11885 & 2900 & 1400 & - & - \\
$\mathrm{Ca}$ (Calcium) & $\mathrm{mg} / \mathrm{kg}$ & ISO 11885 & 38,000 & 11,000 & - & - \\
$\mathrm{K}$ (Potassium) & $\mathrm{mg} / \mathrm{kg}$ & ISO 11885 & 5500 & 3500 & - & - \\
$\mathrm{Na}$ (Sodium) & $\mathrm{mg} / \mathrm{kg}$ & ISO 11885 & 2100 & 260 & - & - \\
$\mathrm{Fe}$ (Iron) & $\mathrm{mg} / \mathrm{kg}$ & ISO 11885 & 6500 & 1500 & - & - \\
$\mathrm{Si}$ (Silicon) & $\mathrm{mg} / \mathrm{kg}$ & ISO 11885 & 25,000 & 9700 & - & - \\
$\mathrm{S}$ (Sulphur) & $\mathrm{mg} / \mathrm{kg}$ & ISO 11885 & 910 & 200 & - & $<120$ \\
$\mathrm{~Pb}$ (Lead) & $\mathrm{mg} / \mathrm{kg}$ & ISO 17294-2 & 66 & 20 & $<150$ & $<1$ \\
$\mathrm{Cd}$ (Cadmium) & $\mathrm{mg} / \mathrm{kg}$ & ISO 17294-2 & $<0.2$ & $<0.2$ & $<1.5$ & $<100$ \\
$\mathrm{Cu}$ (Copper) & $\mathrm{mg} / \mathrm{kg}$ & ISO 17294-2 & 100 & 6 & $<100$ & $<30$ \\
$\mathrm{Ni}$ (Nickel) & $\mathrm{mg} / \mathrm{kg}$ & ISO 17294-2 & 9 & 8 & $<50$ & $<1$ \\
$\mathrm{Hg}$ (Mercury) & $\mathrm{mg} / \mathrm{kg}$ & DIN EN 1483 & $<0.07$ & $<0.07$ & $<1$ & $<400$ \\
Zn (Zinc) & $\mathrm{mg} / \mathrm{kg}$ & ISO 17294-2 & 340 & 84 & $<400$ & $<80$ \\
$\mathrm{Cr}$ (Chromium total) & $\mathrm{mg} / \mathrm{kg}$ & ISO 17294-2 & 22 & 15 & $<90$ & - \\
$\mathrm{B}$ (Boron) & $\mathrm{mg} / \mathrm{kg}$ & ISO 17294-2 & 32 & 10 & - & - \\
$\mathrm{Mn}$ (Manganese) & $\mathrm{mg} / \mathrm{kg}$ & ISO 17294-2 & 350 & 380 & - & - \\
\hline
\end{tabular}

EBC biochar base and premium report the limits required by the EBC protocol of certification. The total ash content ranged between $6.2 \%$ and $18.8 \%(\mathrm{w} / \mathrm{w})$ for biochar from pellets of olive and hazelnut wood. The nutrient content is much greater in hazelnut biochar than olive, which was evident especially for $\mathrm{Mg}, \mathrm{Ca}, \mathrm{Fe}, \mathrm{S}, \mathrm{Cu}$, and $\mathrm{Zn}$. Biochar from hazelnut pellets could bring a greater contribution of nutrients to the soil and, therefore, be less resistant to microbial decomposition. Heavy metal content in both biochars was well below the EBC limits. Only $\mathrm{Cu}$ in the hazelnut biochar was close to the maximum value established by the EBC. 


\subsection{PAHs (Polycyclic Aromatic Hydrocarbons) Composition}

PAHs are ubiquitous in the environment, being by-products of the incomplete combustion of organic material [40]. The chemical structure of PAHs makes them highly resistant to biodegradation and oxidation [41]. The presence of PAHs in pyrolytic reactions above $700^{\circ} \mathrm{C}$ is well established [42], although they can be produced in pyrolysis reactions of less than $700{ }^{\circ} \mathrm{C}$ at low concentration [43]. It is, therefore, critical to ensure PAH concentrations remain below the limits established by the EBC. The 16 priority US EPA PAHs are typically used to assess the total PAH content; the limits established by the EBC are of $<12$ and $<4 \mathrm{mg} / \mathrm{kg}$ for biochar standard and premium, respectively. The PAH composition of the two biochars analysed in this study (Table 6), shows that both biochars are well below the EBC limits, with values ranging from $<0.1$ to $1.1 \mathrm{mg} / \mathrm{Kg}$.

Table 6. PAHs determination from toluene extract.

\begin{tabular}{|c|c|c|c|c|c|c|}
\hline \multirow{2}{*}{ Elements } & \multirow{2}{*}{ Units } & \multirow{2}{*}{ Methods } & \multicolumn{2}{|c|}{ Limits } & \multirow{2}{*}{$\begin{array}{c}\text { Hazelnut } \\
\text { Biochar }\end{array}$} & \multirow{2}{*}{$\begin{array}{c}\text { Olive } \\
\text { Biochar }\end{array}$} \\
\hline & & & GW 1 * & GW 2 * & & \\
\hline Naphthalene & $\mathrm{mg} / \mathrm{kg}$ & DIN EN 15527 & - & - & 0.9 & 1.1 \\
\hline Acenaphthylene & $\mathrm{mg} / \mathrm{kg}$ & DIN EN 15527 & - & - & $<0.1$ & $<0.1$ \\
\hline Acenaphthene & $\mathrm{mg} / \mathrm{kg}$ & DIN EN 15527 & - & - & $<0.1$ & $<0.1$ \\
\hline Fluorene & $\mathrm{mg} / \mathrm{kg}$ & DIN EN 15527 & - & - & $<0.1$ & $<0.1$ \\
\hline Phenanthrene & $\mathrm{mg} / \mathrm{kg}$ & DIN EN 15527 & - & - & 0.3 & 0.3 \\
\hline Anthracene & $\mathrm{mg} / \mathrm{kg}$ & DIN EN 15527 & - & - & $<0.1$ & $<0.1$ \\
\hline Fluoranthene & $\mathrm{mg} / \mathrm{kg}$ & DIN EN 15527 & - & - & 0.1 & 0.1 \\
\hline Pyrene & $\mathrm{mg} / \mathrm{kg}$ & DIN EN 15527 & - & - & 0.1 & 0.1 \\
\hline Benz(a)anthracene & $\mathrm{mg} / \mathrm{kg}$ & DIN EN 15527 & - & - & $<0.1$ & $<0.1$ \\
\hline Chrysene & $\mathrm{mg} / \mathrm{kg}$ & DIN EN 15527 & - & - & $<0.1$ & $<0.1$ \\
\hline Benzo(b)fluoranthene & $\mathrm{mg} / \mathrm{kg}$ & DIN EN 15527 & - & - & $<0.1$ & $<0.1$ \\
\hline Benzo(k)fluoranthene & $\mathrm{mg} / \mathrm{kg}$ & DIN EN 15527 & - & - & $<0.1$ & $<0.1$ \\
\hline Benzo(a)pyrene & $\mathrm{mg} / \mathrm{kg}$ & DIN EN 15527 & - & - & $<0.1$ & $<0.1$ \\
\hline Indeno(1,2,3-cd)pyrene & $\mathrm{mg} / \mathrm{kg}$ & DIN EN 15527 & - & - & $<0.1$ & $<0.1$ \\
\hline Dibenz(a,h)anthracene & $\mathrm{mg} / \mathrm{kg}$ & DIN EN 15527 & - & - & $<0.1$ & $<0.1$ \\
\hline Benzo(g,h,i)perylene & $\mathrm{mg} / \mathrm{kg}$ & DIN EN 15527 & - & - & $<0.1$ & $<0.1$ \\
\hline SUM PAHs (EPA) & $\mathrm{mg} / \mathrm{kg}$ & calculated & $<12$ & $<4$ & 1.20 & 1.60 \\
\hline
\end{tabular}

Total PAH content of the two biochars are 1.2 and $1.6 \mathrm{mg} / \mathrm{kg}$ for olive and hazelnut, respectively. Therefore, both biochars can be considered suitable for soil applications, since both are well below the EBC threshold limit of $4 \mathrm{mg} / \mathrm{kg}$ for biochar premium.

\section{5. $\mathrm{pH}$, Electrical Conductivity (EC), and Density}

In general, the $\mathrm{pH}$ of biochar is relatively homogeneous and varies from neutral to basic $\mathrm{pH}$. Feedstock of various origins produce biochar with an average $\mathrm{pH}$ between 6.2 and 9.6 [39]. Lower $\mathrm{pH}$ is typically found for biochars obtained from green pruning feedstock and organic waste, while the highest values are to be attributed to poultry litter biochar. The Table 7 reports the elements values, according to their $\mathrm{pH}$, electrical conductivity, salt content and density.

The two biochar have a $\mathrm{pH}$ of 8.4 and 9.9 for olive and hazelnut, respectively. The EBC indicates a maximum limit of 10; therefore, biochar produced from these types of wood residues is slightly below the limit established by the certification. The EC is of particular importance when adding biochar to soils with high EC and salinity. The two biochars had an EC of 217 and $332 \mathrm{mS} / \mathrm{cm}$, respectively, for olive and hazelnut (as shown in Table 7). Both values are very low and do not represent a real risk for the addition to soil even under conditions of high EC. In general, biochar has a lower density than soil, with an average of $0.4 \mathrm{~g} \cdot \mathrm{cm}^{-3}$ compared to a soil of medium texture, with average of $1.3 \mathrm{~g} \cdot \mathrm{cm}^{-3}$. When adding biochar to soils with little ventilation, this property can help to reduce the density by 
mitigating issues related to the compaction of soil. The olive and hazelnut biochars produced in this study have a density of 0.45 and $0.44 \mathrm{~g} \cdot \mathrm{cm}^{-3}$, respectively.

Table 7. Elements value (pH, electrical conductivity, and density).

\begin{tabular}{cccc}
\hline Elements & Units & Hazelnut Biochar & Olive Biochar \\
\hline $\mathrm{pH}$ values $\left(\mathrm{CaCl}_{2}\right)$ & - & 9.9 & 8.4 \\
Electrical conductivity & $\mu \mathrm{S} / \mathrm{cm}$ & 332 & 217 \\
Salt content & $\mathrm{g} / \mathrm{kg}$ & 0.655 & 1.18 \\
Salt content cal. with bulk density & $\mathrm{g} / \mathrm{L}$ & 0.287 & 0.527 \\
\hline
\end{tabular}

\section{Conclusions}

The two biochars analysed in this study show excellent physicochemical properties, which makes them suitable for agricultural applications. Both biochars can be certified as Biochar Premium according to the regulations of the EBC; this allows a potential commercialisation of the biochars, with higher prices than Biochar Base, typically less expensive, but with a higher content of PAHs. The benefits of using Biochar Premium as soil fertiliser includes improved productivity, increased water holding capacity of the soil (e.g., [44-46]), and a better retention of nutrients and agrochemicals in soils, all of which should offset initial investment and provide added profits per application. Biochar fuel commands a high-value application, offering numerous benefits, and an authentic alternative to develop the biomass utilization efficiency [4,47]. The added value of biochar is also linked to other issues, such as those involving agricultural and environmental sustainability. As claimed by many studies [1,16], biochar as a soil amendment can improve soil health and increase agricultural productivity with further environmental benefits related to global warming mitigation [16,48-52]. Based on our results, we intend to define an agro-forestry chain to use the residual waste biomass for the production of high quality biochar for agronomic and commercial purposes. We are proceeding to evaluate the properties of biochar for soil improvement.

Acknowledgments: This work was supported during my visiting professor at Strathclyde University.

Author Contributions: All authors contributed equally to the work done.

Conflicts of Interest: The authors declare no conflict of interest.

\section{References}

1. Lehmann, J.; Stephen, J. Biochar for Environmental Management-Science and Technology; Routledge: Abingdon, UK, 2009.

2. Sohi, S.; Lopez-Capel, E.; Krull, E.; Bol, R. Biochar, climate change and soil: A review to guide future research. Civ. Eng. 2009, 6618-6664.

3. Manyà, J.J. Pyrolysis for biochar purposes: A review to establish current knowledge gaps and research needs. Environ. Sci. Technol. 2012, 46, 7939-7954. [CrossRef] [PubMed]

4. Anupam, K.; Sharma, A.K.; Lal, P.S.; Dutta, S.; Maity, S. Preparation, characterization and optimization for upgrading Leucaena leucocephala bark to biochar fuel with high energy yielding. Energy 2016, 106, 743-756.

5. Jahirul, M.I.; Rasul, M.G.; Chowdhury, A.A.; Ashwat, N. Biofuels production through biomass pyrolysis-A technological review. Energies 2012, 5, 4952-5001. [CrossRef]

6. Hoogwijk, M.; Faaij, A.P.C.; van den Broek, R.; Berndes, G.; Gielen, D.; Turkenburg, W. Exploration of the ranges of the global potential of biomass for energy. Biomass Bioenergy 2003, 25, 119-133. [CrossRef]

7. Panwar, N.L.; Kothari, R.; Tyagi, V.V. Thermo chemical conversion of biomass - Eco friendly energy routes. Renew. Sustain. Energy Rev. 2012, 16, 1801-1816. [CrossRef]

8. Demirbas, A. Partly chemical analysis of liquid fraction of flash pyrolysis products from biomass in the presence of sodium carbonate. Energy Convers. Manag. 2002, 43, 1801-1809. [CrossRef]

9. Gaunt, J.L.; Lehmann, J. Energy balance and emissions associated with biochar sequestration and pyrolysis bioenergy production. Environ. Sci. Technol. 2008, 42, 4152-4158. [CrossRef] [PubMed] 
10. Singh, B.P.; Cowie, A.L. A novel approach, using ${ }^{13} \mathrm{C}$ natural abundance, for measuring decomposition of biochars in soil. In Proceedings of the Carbon and Nutrients Management in Agriculture, Palmerston North, New Zealand, 13-14 February 2008; Currie, L.D., Yates, L., Eds.

11. Steinbeiss, S.; Gleixner, G.; Antonietti, M. Effect of biochar amendment on soil carbon balance and soil microbial activity. Soil Biol. Biochem. 2009, 41, 1301-1310. [CrossRef]

12. Di Blasi, C.; Branca, C.; Lombardi, V.; Ciappa, P.; di Giacomo, C.; Chimica, I. Effects of particle size and density on the packed-bed pyrolysis of wood. Energy Fuels 2013, 27, 6781-6791. [CrossRef]

13. Brewer, C.; Schmidt-Roht, K.; Satrio, J.; Brown, R. Characterization of Biochar from fast pyrolysis and gasification systems. Environ. Prog. 2009, 28, 386-396. [CrossRef]

14. Sánchez, M.E.; Lindao, E.; Margaleff, D.; Martínez, O.; Morán, A. Pyrolysis of agricultural residues from rape and sunflowers: Production and characterization of bio-fuels and biochar soil management. J. Anal. Appl. Pyrolysis 2009, 85, 142-144. [CrossRef]

15. Keiluweit, M.; Nico, P.S.; Johnson, M.G.; Kleber, M. Dynamic molecular structure of plant biomass-derived black carbon (biochar). Environ. Sci. Technol. 2010, 44, 1247-1253. [CrossRef] [PubMed]

16. Agegnehu, G.; Bass, A.M.; Nelson, P.N.; Muirhead, B.; Wright, G.; Bird, M.I. Biochar and biochar-compost as soil amendments: Effects on peanut yield, soil properties and greenhouse gas emissions in tropical North Queensland, Australia. Agric. Ecosyst. Environ. 2015, 21, 372-385. [CrossRef]

17. Beesleya, L.; Moreno-Jiménez, E.; Gomez-Eyles, J.L.; Harris, E.; Robinsond, B.; Sizmure, T. A review of biochars' potential role in the remediation, revegetation and restoration of contaminated soils. Environ. Pollut. 2011, 159, 3269-3282. [CrossRef] [PubMed]

18. Laird, D.A.; Fleming, P.; Davis, D.D.; Horton, R.; Wang, B.; Karlen, D.L. Impact of biochar amendments on the quality of a typical Midwestern agricultural soil. Geoderma 2010, 158, 443-449. [CrossRef]

19. Lehmann, J. A handful of carbon. Nature 2007, 447, 143-144. [CrossRef] [PubMed]

20. Di Giacomo, G.; Taglieri, L. Renewable energy benefits with conversion of woody residues to pellets. Energy 2009, 34, 724-731. [CrossRef]

21. Colantoni, A.; Longo, L.; Evic, N.; Gallucci, F.; Delfanti, L. Use of Hazelnut's pruning to produce biochar by gasifier small scale plant. Int. J. Renew. Energy Res. 2015, 5, 873-878.

22. Di Giacinto, S.; Longo, L.; Menghini, G.; Delfanti, L.; Egidi, G.; de Benedictis, L.; Riccioni, S.; Salvati, L. Model for estimating pruned biomass obtained from Corylus avellana L. Appl. Math. Sci. 2014, 8, 6555-6564.

23. White, J.E.; Catall, W.J.; Legendre, B.L. Biomass pyrolysis kinetics: A comparative critical review with relevant agricultural residue case studies. Anal. Appl. Pyrol. 2011. [CrossRef]

24. Kloss, S.; Zehetner, F.; Dellantonio, A.; Hamid, R.; Ottner, F.; Liedtke, V.; Schwanninger, M.; Gerzabek, M.H.; Soja, G. Characterization of slow pyrolysis biochars: Effects of feedstocks and pyrolysis temperature on biochar properties. J. Environ. Qual. 2012, 41, 990-1000. [CrossRef] [PubMed]

25. Gaskin, J.W.; Steiner, C.; Harris, K.; Das, K.C.; Bibens, B. Effect of low-temperature pyrolysis conditions on biochar for agricultural use. Trans. Asabe 2008, 51, 2061-2069. [CrossRef]

26. Novak, J.; Lima, I.; Xing, B. Characterization of designer biochar produced at different temperatures and their effects on a loamy sand. Ann. Environ. Sci. 2009, 3, 195-206.

27. Ceylan, R.; B-son Bredenberg, J. Hydrogenolysis and hydrocracking of the car-bonoxygen bond. 2. Thermal cleavage of the carbon-oxygen bond in guaiacol. Fuel 1982, 61, 377-382.

28. Jothibasu, K.; Mathivanan, G. Enhancing combustion efficiency using nano nickel oxide catalyst in biomass gasifier. Int. J. Core Eng. Manag. (IJCEM) 2015, 2, 31-41.

29. Laird, D.A. Review of the pyrolysis platform for coproducing bio-oil and biochar. Biofuels Bioprod. Bioref. 2008, 3, 547-562. [CrossRef]

30. European Biochar Certificate (EBC). Guidelines for a Sustainable Production of Biochar; European Biochar Foundation: Arbaz, Switzerland, 2012; pp. 1-23.

31. European Parliament, Council of the European Union. Regulation (EC) No. 1907/2006 of the European Parliament and of the Council of 18 December 2006 concerning the Registration, Evaluation, Authorisation and Restriction of Chemicals (REACH), establishing a European Chemicals Agency, amending Directive 1999/45/EC and repealing Council Regulation (EEC) No 793/93 and Commission Regulation (EC) No 1488/94 as well as Council Directive 76/769/EEC and Commission Directives 91/155/EEC, 93/67/EEC, 93/105/EC and 2000/21/EC. Available online: http://eur-lex.europa.eu/legal-content/EN/TXT/?uri= CELEX\%3A02006R1907-20140410 (accessed on 10 April 2014). 
32. Demirbas, A. Effects of temperature and particle size on bio-char yield from pyrolysis of agricultural residues. J. Anal. Appl. Pyrolysis 2004, 72, 243-248. [CrossRef]

33. Hammes, K.; Smernik, R.J.; Skjemstad, J.O.; Herzog, A.; Vogt, U.F.; Schmidt, M.W.I. Synthesis and characterisation of laboratory-charred grass straw (Oryza sativa) and chestnut wood (Castanea sativa) as reference materials for black carbon quantification. Org. Geochem. 2006, 37, 1629-1633. [CrossRef]

34. Krevelen, V. Coal Science; Elsevier: Amsterdam, The Netherlands, 1957.

35. Chun, Y.; Sheng, G.; Chiou, G.T.; Xing, B. Compositions and sorptive properties of crop residue-derived chars. Environ. Sci. Technol. 2004, 38, 4649-4655. [CrossRef] [PubMed]

36. Kuhlbusch, T.A.J.; Crutzen, P.J. Toward a global estimate of black carbon in residues of vegetation fires representing a sink of atmospheric $\mathrm{CO}_{2}$ and a source of $\mathrm{O}_{2}$. Glob. Biogeochem. Cycles 1995, 9, 491-501. [CrossRef]

37. Laine, J.; Yunes, S. Effect of the preparation method on the pore size distribution of activated carbon from coconut shell. Carbon N. Y. 1992, 30, 601-604. [CrossRef]

38. Schimmelpfennig, S.; Glaser, B. One step forward toward characterization: Some important material properties to distinguish biochars. J. Environ. Qual. 2012, 41, 1001-1013. [CrossRef] [PubMed]

39. Chan, K.Y.; Xu, Z. Biochar: Nutrient properties and their enhancement. Biochar Environ. Manag. Sci. Technol. 2012, 67-84.

40. Keith, L.H.; Telliard, W.A. Priority pollutants I-a perspective view. Environ. Sci. Technol. 1979, 13, 416-423. [CrossRef]

41. Preston, C.M.; Schmidt, M.W.I. Black (pyrogenic) carbon: A synthesis of current knowledge and uncertainties with special consideration of boreal regions. Biogeosciences 2006, 3, 397-420. [CrossRef]

42. Ledesma, E.B.; Marsh, N.D.; Sandrowitz, A.K.; Wornat, M.J. Global kinetic rate parameters for the formation of polycyclic aromatic hydrocarbons from the pyrolysis of catechol, a model compound representative of solid fuel moieties. Energy Fuels 2002, 16, 1331-1336. [CrossRef]

43. Garcia-Perez, M. The Formation of Polyaromatic Hydrocarbons and Dioxins during Pyrolysis: A Review of the Literature with Descriptions of Biomass Composition, Fast Pyrolysis Technologies and Thermochemical Reactions; Washington State University: Pullman, WA, USA, 2008; pp. 1-58.

44. Fellet, G.; Marchiol, L.; delle Vedove, G.; Peressotti, A. Application of biochar on mine tailings: Effects and perspectives for land reclamation. Chemosphere 2011, 83, 1262-1267. [CrossRef] [PubMed]

45. Karhu, K.; Mattila, T.; Bergstrom, I.; Regina, K. Biochar addition to agricultural soil increased CH4 uptake and water holding capacity—Results from a short-term pilot field study. Agric. Ecosyst. Environ. 2011, 140, 309-313. [CrossRef]

46. Streubel, J.D.; Collins, H.P.; Garcia-Perez, M.; Tarara, J.; Granatstein, D.; Kruger, C.E. Influence of contrasting biochar types on five soils at increasing rates of application. Soil Sci. Soc. Am. J. 2011, 75, 1402-1413. [CrossRef]

47. Liu, Z.; Quek, A.; Hoekman, S.K.; Balasubramanian, R. Production of solid biochar fuel from waste biomass by hydrothermal carbonization. Fuel 2013, 103, 943-949. [CrossRef]

48. Reza, M.T.; Andert, J.; Wirth, B.; Busch, D.; Pielert, J.; Lynam, J.G.; Mumme, J. Hydrothermal carbonization of biomass for energy and crop production. Appl. Bioenergy 2014, 1, 11-29. [CrossRef]

49. Hill, J.; Nelson, E.; Tilman, D.; Polasky, S.; Tiffany, D. Environmental, economic, and energetic costs and benefits of biodiesel and ethanol biofuels. Proc. Natl. Acad. Sci. USA 2006, 103, 11206-11210. [CrossRef] [PubMed]

50. Chandra, R.; Takeuchi, H.; Hasegawa, T. Hydrothermal pretreatment of rice straw biomass: A potential and promising method for enhanced methane production. Appl. Energy 2012, 94, 129-140. [CrossRef]

51. Kim, D.; Yoshikawa, K.; Park, K.Y. Characteristics of biochar obtained by hydrothermal carbonization of cellulose for renewable energy. Energies 2015, 8, 14040-14048. [CrossRef]

52. Civitarese, V.; Spinelli, R.; Barontini, M.; Gallucci, F.; Santangelo, E.; Acampora, A.; Scarfone, A.; del Giudice, A.; Pari, L. Open-air drying of cut and windrowed short-rotation poplar stems. Bioenergy Res. 2015, 8, 1614-1620. [CrossRef]

(C) 2016 by the authors; licensee MDPI, Basel, Switzerland. This article is an open access article distributed under the terms and conditions of the Creative Commons Attribution (CC-BY) license (http://creativecommons.org/licenses/by/4.0/). 